\title{
Friction and Wear of Restorative Dental Materials
}

\author{
E. W. TILLITSON, R. G. CRAIG, and F. A. PEYTON \\ School of Dentistry, University of Michigan, Ann Arbor, Michigan 48104, USA
}

Friction coefficients for a variety of material couples are reported. The relative abrasive wear of materials followed the order of their hardness, with one exception.

Many different instruments have been developed for the measurement of friction and wear. ${ }^{1-5}$ Often the instrument was designed to accommodate some particular type of material, environment, or test condition. Studies reported in the dental literature have been limited to wear measurements with simulated toothbrushing methods, ${ }^{6-9}$ or on prosthetic teeth mounted on an articulator. ${ }^{10}$

This study will describe the experimental instrumentation for tests under a variety of variables, as well as simulated mouth conditions. Friction and wear measurements of a variety of restorative dental materials also will be reported.

\section{Materials and Methods}

A hydraulic surface grinder* was selected to provide the sliding motion between the samples under study. The surface grinder with samples in position is shown in Figure 1. It had the following specifications: The longitudinal table speed could be varied from 3 inches to $150 \mathrm{feet} /$ minute, and had a travel of 23.5 inches. Table travel in a transverse direction was 6.75 inches and the actual working surface was 6 by 18 inches. By appropriate adjustments the table can be controlled at speeds as low as $0.002 \mathrm{~cm} /$

-This investigation was supported by USPHS Research Grant DE-02415 from the National Institute for Dental Research, National Institutes of Health, Bethesda, Md.

Presented in part at the 47 th and 48th General Meetings of the International Association for Dental $\mathrm{Re}$ search, March 1969 and 1970 at Houston, Tex and New York, NY.

Received for publication May 11, 1970.

* Model \#250 Grand Rapids Hydraulic Feed Surface Grinder, Gallmeyer and Livingston Co., Grand Rapids, Mich. second. In addition, the machine controls may be set so the table undergoes an adjustable transverse motion near the end of each stroke. Friction and wear tests could be made on a continuously fresh track or the same track may be retraced; in the latter instance, tests could be made to study the effect of accumulating wear particles on friction and wear.

The basic machine was modified by adding a pair of heavy horizontal extension arms to support the instrumentation over the table. The instrumentation consisted of a frictional force transducer, sample supports, and a means of counterbalancing the sample and its supports. The transducer consisted of a cantilever beam with strain gauges attached to each side to form a full bridge shown in Figure 2. The end of the beam carried collet chucks for the rod samples having hemispheric ends. The cantilever beam rod operated as a linear motion bearing that was supported in two ball bushings with adjustable clearances. The adiustment was provided by mounting the bushings in a split aluminum block. The top of the transducer rod supported a pan for weights. A small horizontal rod, one end of which was confined to a vertical slot near the top of the transducer rod, prevented rotation.

The surface grinder, as purchased, had a minimum stroke length of 2 inches but was modified to permit strokes as short as $1 / 16$ inch. The limit switch consisted of a sliding post and two adjustable microswitches that permitted the sample to be mounted anywhere on the working surface of the table. Each microswitch controlled a $12 \mathrm{v}$ solenoid, which in turn moved the mechanical reversing lever. The switches were protected from arcing by shorting them with $16 \mathrm{v}$ zener diodes. The short strokes provided a means for testing single teeth.

The displacement and table velocity for short strokes was measured with a dial gauge 


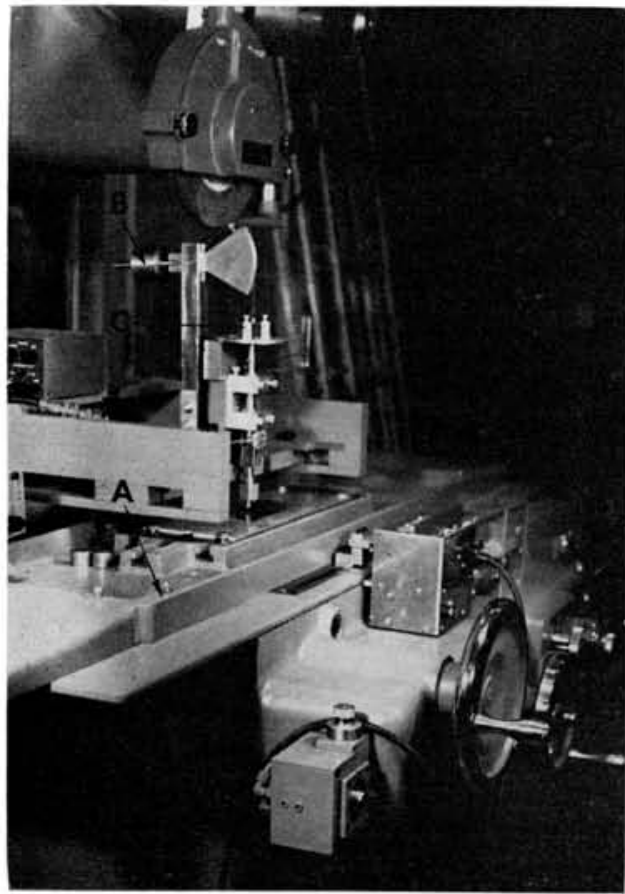

Fig 1.-Overall view of the friction and wear instruments. $A$, table; $B$, counterbalance; $C$, weights.

and a stop watch if the velocities were relatively low. The displacement for longer strokes and greater velocities were determined by a displacement transducer, with the output fed into a $y$ - $t$ recorder. The transducer was a ten turn potentiometer, the shaft of which was connected to the table motion through a wire wrapped once around a shaft-mounted pulley. Tests under simulated oral conditions were conducted using saliva and other liquids placed on the samples.

The hemispheric tipped rods of one-fourth inch diameter were formed by mounting the sample on a lathe and using a radius cutter,* or they were molded in a dental stone mold. The lower flat samples were finished by wet grinding on 600 mesh silicon carbide paper, which yielded surfaces with roughnesses of 3 to 6 microinches. A 2 by 5 by $1 / 16$ inch sheet of amalgam was prepared using an extension of a method developed by Schoenfeld and Greener. ${ }^{11}$ Two hundred grams of

- Holdridge Radii cutter, Model 3S, Holdridge Mfg. Co., 116 West 154th St., Gardena, Calif.

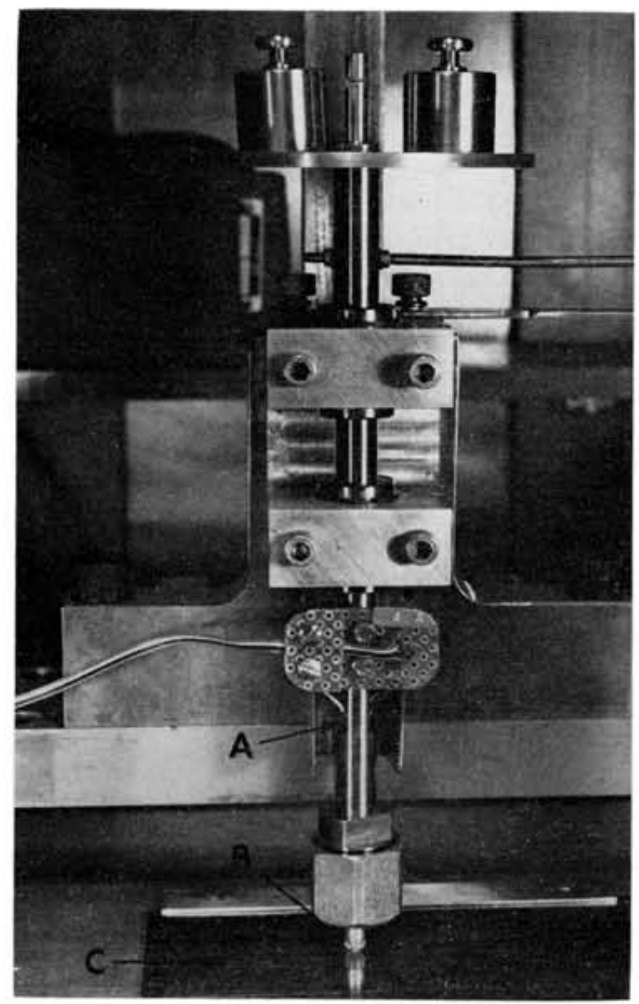

FIG 2.-Close up of the strain gauge transducer $(A)$, slider $(B)$, and flat $(C)$.

alloy $\dagger$ and mercury in a 1:1 ratio were amalgamated using a chilled mortar and pestle and subsequently storing in Dry Ice. Samples of this mix were withdrawn serially and condensed into a sheet of the aforementioned dimensions. Sheets of gold alloy, $\ddagger$ porcelain, $\S$ and resin composites\| were supplied by dental manufacturers. Acrylic sheets of denture base plastic \# were processed by typical heat-curing dental laboratory procedures, and bovine enamel specimens were prepared as described by Eden, Craig, and Peyton. ${ }^{12}$ Sheets of a chromium-nickel alloy were prepared by investment casting.

The coefficients of friction $(\mu)$ were determined by measuring the horizontal force $(F)$ required to produce a motion of the flat specimen when held in contact with the

\footnotetext{
$\dagger$ New True Dentalloy, S. S. White Co., Philadelphia,

‡ Oro B-2, J. M. Ney Co., Bloomfield, Conn.

\$ Bioform, Dental Supply Co., York, Pa.

II Addent 35, 3M Company, St. Paul, Minn.

\# Lucitone, L. D. Caulk, Milford, Del.

f Regalloy, Ransom \& Randolph Co., Toledo Ohio.
} $\mathrm{Pa}$. 
hemispheric specimen and dividing this force by the load $(W)$ on the specimen, $\mu=F / W$.

Abrasion was evaluated on a preliminary basis using a standard tester.* The samples were run in the dry condition, although the zinc phosphate cement sample was stored in a humidor between the time of preparation and testing.

\section{Results}

The coefficient of friction of bovine enamel on a variety of materials in the absence (dry) and presence of saliva (wet) are shown in Table 1 . The values for gold, amalgam, acrylic, and chromium-nickel alloy in the wet condition are not listed because no effect was observed. The coefficient of friction for bovine enamel against porcelain, bovine enamel, and bovine dentin were higher in the wet than the dry condition; this was especially true for porcelain. The sliding velocities varied from 0.02 to 3.75 $\mathrm{cm} /$ second, but no correlation was observed between velocity and friction coefficient. The load varied from 100 to $1,000 \mathrm{gm}$ and the coefficient of friction increased with load with couples that produced wear particles, such as acrylic resin and bovine enamel.

The friction of gold alloy on several materials is given in Table 2. In all but one instance, the tests were run by retracing the same wear track. The friction coefficients for gold on gold had a wide range; the lower values were obtained at the start of the test and the values gradually increased as the track was retraced. When the test was stopped, the track washed with acetone and dried, and the test continued, an immediate

TABLE 1

CoEfFicient of Friction of a Hemispheric SaMPLE of Bovine ENaMEL on Materials

\begin{tabular}{lcc}
\hline \hline \multirow{2}{*}{$\begin{array}{c}\text { Lower Flat } \\
\text { Test Specimen }\end{array}$} & \multicolumn{2}{c}{ Coefficient of Friction } \\
\cline { 2 - 3 } Gold & $0.12-0.20$ & Wet \\
Amalgam & $0.18-0.22$ & $\ldots$ \\
$\begin{array}{l}\text { Denture base } \\
\quad \text { acrylic }\end{array}$ & $0.19-0.65$ & $\ldots$ \\
Chromium-nickel & & $\ldots$ \\
$\quad$ alloy & $0.10-0.12$ & $\ldots$ \\
Porcelain & $0.10-0.12$ & $0.50-0.90$ \\
Bovine dentin & $0.35-0.40$ & $0.45-0.55$ \\
Bovine enamel & $0.22-0.60$ & $0.50-0.60$ \\
\hline
\end{tabular}

* Taber Abraser (CS-17 Calibrase Wheels), Taber Instrument Company, North Tonowanda, NY. decrease of the friction coefficient to 0.28 was observed. A similar observation was made when the friction coefficients of gold on acrylic resin were determined by retracing the same track; $\mu$ varied from 0.6 to 0.8 . When the coefficient of friction was made on a fresh surface the values ranged from 0.5 to 0.6 .

The friction coefficients for gold on dry porcelain were 0.22 to 0.25 ; the presence of water caused a reduction of the value to 0.16 to 0.17 . During the sliding of gold on amalgam, the amalgam was found to transfer to the gold slider and as a result it would be expected the coefficient of friction $(0.15$ to 0.25 ) should be in the region of amalgam on amalgam.

Tests for amalgam on various materials are shown in Table 3 and in general the friction was low with fairly large variations for amalgam on gold, amalgam, and bovine enamel. The variation of friction for amalgam on gold as a function of load and the number of strokes is shown in Figure 3. Higher loads resulted in higher friction values, up to about 30 strokes, and within this range the friction increased more rapidly at the higher loads. For 30 or more strokes no difference in friction was observed as a function of load, and the scatter in the results increased.

The values for amalgam on amalgam were examined in greater detail and a plot of the coefficient of friction as a function of load at two sliding velocities is shown in Figure 4. Each point is the average of 20 data points in a single experimental run. The variation in friction was greater for low loads, but no significant effect of load or sliding velocity on friction was observed in this range. If all the points are treated together a mean coefficient of friction of 0.24 with a $95 \%$ confidence limit of \pm 0.02 was obtained. Microscopic examination of wear tracks showed that amalgam functioned as a ductile substance at low loads, 100 to $500 \mathrm{gm}$, and as a brittle substance at high loads of 2,000 $\mathrm{gm}$. The wear track for amalgam sliding on amalgam under a 2,000 gm load is shown in Figure 5, where the surface cracks at right angles to the travel of the slider indicate brittle failure.

The values for amalgam on porcelain showed that water had little influence on the friction and that load or velocity had 
TABLE 2

Friction Tests With Gold Alloy Hemispheric Riders

\begin{tabular}{llccc}
\hline \hline $\begin{array}{c}\text { Lower } \\
\text { Flat Test } \\
\text { Specimens }\end{array}$ & $\begin{array}{c}\text { Interface } \\
\text { Condition }\end{array}$ & $\begin{array}{c}\text { Velocity } \\
(\mathrm{cm} / \mathrm{sec})\end{array}$ & $\begin{array}{c}\text { Load } \\
(\mathrm{gm})\end{array}$ & $\begin{array}{c}\text { Friction } \\
\text { Coefficient }\end{array}$ \\
\hline Gold & Clean \& dry & $0.16-0.30$ & $100-1,000$ & $0.2-0.6$ \\
Amalgam & Clean \& dry & $0.05-0.40$ & $100-1,500$ & $0.15-0.25$ \\
Porcelain & Clean \& dry & $0.05-2.5$ & $100-1,900$ & $0.22-0.25$ \\
Porcelain & Water & 0.23 & $100-1,900$ & $0.16-0.17$ \\
Acrylic & Clean \& dry & $0.05-2.5$ & $100-700$ & $0.6-0.8$ \\
Acrylic & Clean \& dry* & $0.05-2.7$ & $100-700$ & $0.5-0.6$ \\
\hline
\end{tabular}

* Friction track was not retraced.

TABLE 3

Friction Tests with Amalgam Hemispheric Riders

\begin{tabular}{llccc}
\hline $\begin{array}{c}\text { Lower Flat } \\
\text { Test Specimens }\end{array}$ & $\begin{array}{c}\text { Interface } \\
\text { Condition }\end{array}$ & $\begin{array}{c}\text { Velocity } \\
(\mathrm{cm} / \mathrm{sec})\end{array}$ & $\begin{array}{c}\text { Load } \\
(\mathrm{gm})\end{array}$ & $\begin{array}{c}\text { Friction } \\
\text { Coefficient }\end{array}$ \\
\hline Gold & Water & $0.03-0.97$ & $100-2,000$ & $0.10-0.35$ \\
Amalgam & Clean \& dry & $0.002-0.05$ & $100-2,000$ & $0.19-0.35$ \\
Porcelain & Clean \& dry & $0.06-0.34$ & $100-1,000$ & $0.06-0.12$ \\
Porcelain & Water & $0.06-0.34$ & $100-2,000$ & $0.07-0.15$ \\
Resin composite & Water & $0.004-0.92$ & $100-2,000$ & $0.10-0.18$ \\
Bovine enamel & Water & $0.007-0.73$ & $100-2,000$ & $0.12-0.28$ \\
\hline
\end{tabular}

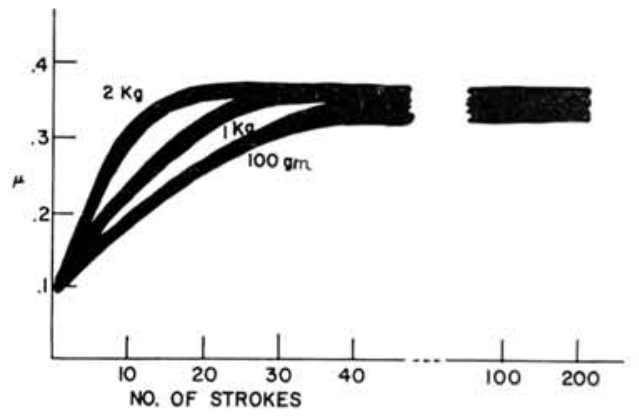

FIG 3.-Friction coefficient $(\mu)$ of amalgam on gold alloy as a function of the number of repetitive strokes for three loads.

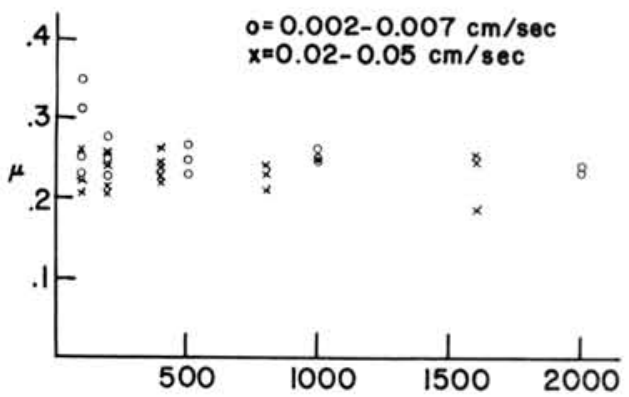

FIG 4.-Friction coefficient $(\mu)$ for amalgam on amalgam as a function of load and sliding velocity.

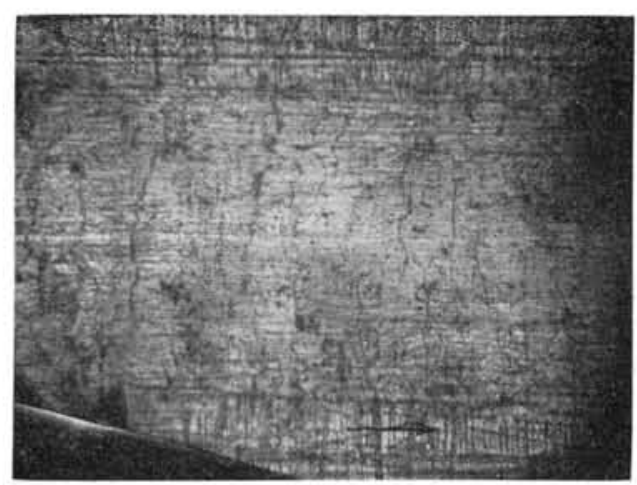

FIG 5.-Brittle behavior of amalgam at higher loads.

little effect on the friction of amalgam on porcelain or resin composite.

The friction tests for a resin composite on various surfaces are given in Table 4 . The presence of water elevated the friction coefficient, but the effect of sliding velocity and load was negligible. Again, it was noted that amalgam was transferred to the composite slider and the friction coefficient should be in the region of amalgam on amalgam. The resin composite on bovine enamel exhibited behavior similar to amalgam on gold (Fig 3 ) with the added feature that the friction coefficient increased rapidly from 
TABLE 4

Friction Tests WITH REsin COMPOSITE HeMISPhERIC RIDERS

\begin{tabular}{llccc}
\hline $\begin{array}{c}\text { Lower } \\
\text { Flat Test } \\
\text { Specimens }\end{array}$ & $\begin{array}{c}\text { Interface } \\
\text { Condition }\end{array}$ & $\begin{array}{c}\text { Velocity } \\
(\mathrm{cm} / \mathrm{sec})\end{array}$ & $\begin{array}{c}\text { Load } \\
(\mathrm{gm})\end{array}$ & $\begin{array}{c}\text { Friction } \\
\text { Coefficient }\end{array}$ \\
\hline Amalgam & Water & $0.03-0.69$ & $100-2,500$ & $0.22-0.34$ \\
Amalgam & Clean \& dry & $0.07-0.69$ & $100-1,000$ & $0.13-0.25$ \\
Bovine enamel & Water & $0.02-0.17$ & $100-2,500$ & $0.30-0.75$ \\
\hline
\end{tabular}

the initial value of 0.3 to a maximum of 0.75 .

Abrasion resistance of several materials to a standard abrasive wheel is listed in Table 5 . The values confirm that volume loss should be used in evaluating abrasion. The increase in the volume loss was in the order of decreasing hardness except for porcelain, which had a higher volume loss than dental amalgam.

\section{Discussion}

The study showed that reporting an average value for the coefficient of friction of a hemispheric slider on a flat surface may be misleading because the value may be a function of load, sliding velocity, transfer of one material to another, wear particle accurnulation, or the presence or absence of water on the surface.

The effect of water on friction, for example, resulted in increases for bovine enamel on porcelain, bovine enamel, and bovine dentin, decreases for gold on porcelain, and no effect for amalgam on porcelain. Other examples were also pointed out in the "results" section. These data suggest that the presence of a polar liquid such as water improves the opportunity for adhesion of surface asperities, thus increasing the frictional force. Further evidence supports this proposal since a similar effect was observed using other polar liquids; methyl alcohol, propyl alcohol, dimethyl sulfoxide and dimethylformamide. If one of the surfaces was nonpolar, water either reduced the friction or had no effect. These observations suggest that adhesion is hindered in these instances, with more hindrance taking place where one of the members is not easily oxidized.

Material couples such as gold on gold showed that the number of repetitive strokes increased the friction. The effect appeared to be a result of the accumulation of wear particles in the track since the friction decreased immediately after cleaning debris from the track. Similar effects were observed for gold on acrylic resin. In these systems, increasing the load also increased the friction and the maximum was reached sooner as a result of the more rapid accumulation of wear particles. The rapid increase in the coefficient of friction for the resin composite on bovine enamel indicated the collection of wear particles in the friction track as the track was retraced. At low loads the materials tended to function in a ductile manner, but they functioned as brittle materials at high loads; this behavior produced wear more rapidly at high loads. The effect of wear particles was also observed by noting higher friction values when the track was retraced rather than making the measurements continuously on a fresh surface.

The transfer of amalgam to the hemispheric slider also affected the friction values. Transfer of amalgam to gold and resin composite sliders resulted in friction values close to those for amalgam on amalgam. Transfer of amalgam to the abrasive wheels of the Taber Abraser may explain why amal-

TABLE 5

Dry Abrasion Resistance Estimated by Weight and Volume Loss

\begin{tabular}{lcccc}
\hline & \multicolumn{4}{c}{ Weight and Volume } \\
\cline { 2 - 5 } \multicolumn{1}{c}{ Material } & gm & Rating & ml & Rating \\
\hline Chromium-nickel alloy & 0.005 & 1 & 0.00067 & 1 \\
Acrylic (Plexiglas) & 0.030 & 6 & 0.0254 & 3.8 \\
Denture base acrylic & 0.030 & 6 & 0.0254 & 3.8 \\
Dental porcelain & 0.033 & 6.5 & 0.013 & 1.9 \\
Zinc phosphate cement & 0.048 & 9.5 & 0.016 & 2.4 \\
Dental amalgam & 0.129 & 26.0 & 0.011 & 1.6 \\
\hline
\end{tabular}


gam had a lower rating than dental porcelain (Table 5).

\section{Conclusions}

Friction coefficients were reported for a variety of material couples commonly used in dentistry. The sliding friction values were determined using a hemispheric slider on a flat surface and measuring the frictional force with a strain gauge transducer. The coefficient of friction was measured at different loads and sliding velocities and under wet and dry conditions. Comparison of material couples in both wet and dry conditions revealed that sometimes water functioned as a lubricant and other times acted to increase the friction. In the latter situation, both the slider and the flat were polar solids. When one of the solids in the couple was nonpolar, water had no effect or functioned as a mild lubricant. The friction of some couples increased with increases in load and the number of repetitive cycles; this effect was principally due to the accumulation of wear particles in the track. One of the factors in lower loads causing less friction is the ductile behavior of materials under these conditions. In general, the sliding velocity in the region studied had less effect on friction than the other variables. Transfer of material from one member of the couple was observed when amalgam was the flat specimen and the slider was gold or resin composite; the friction values for these couples were similar to amalgam on amalgam. The relative abrasive wear of materials followed the order of the hardness of the materials, with the exception of amalgam, the deviance of which probably resulted from transfer of amalgam to the abrasive wheels.

\section{References}

1. Bowden, F.P., and TABor, D.: The Friction and Lubrication of Solids, Vol 1, London: Oxford University Press, 1950, p 72.

2. RABINowiCZ, E.: Friction and Wear of $M a-$ terials, New York: John Wiley, 1965, pp 102-106.

3. Bayer, R.G.; Clinton, W.C.; Nelson, C.W.; and SCHUMACHER, R.A.: Engineering Model for Wear, Wear 5:378-391, 1962.

4. BOWDEN, F.P., and TABOR, D.: Friction and Lubrication, London: Methuen Co. Ltd., 1967, pp 5-7.

5. Furey, M.J.: Friction, Wear and Lubrication, Ind Eng Chem 61(3):12-29, 1969.

6. MANLY, R.S., and BRUdevold, F.: Relative Abrasiveness of Natural and Synthetic Tooth Brush Bristles on Cementum and Dentin, JADA 55:779-780, 1957.

7. MANLY, R.S.; Wreen, J.; MaNly, P.L.; and KEENE, R.C.: A Method for Measurement of Abrasion of Dentin by Toothbrush and Dentifrice, J Dent Res 44:533-540, 1965.

8. NORMAN, R.L.: Frictional Resistance and Dental Prosthetics, J Prosth Dent 14:4551, 1964.

9. MCConnell, D., and Conroy, C.W.: Comparison of Abrasion Produced by a Simulated Manual Versus a Mechanical Toothbrush, J Dent Res 46:1022-1027, 1967.

10. Cornell, J.A.; Jordan, J.S.; Ellis, S.; and Rose, E.E.: A Method of Comparing the Wear Resistance of Various Materials Used for Artificial Teeth, JADA 54:608614, 1957.

11. Schoenfeld, C.M., and Greener, E.H.: Morphology of Initial Stages of Amalgamation as Revealed by Low Temperature Techniques, abstracted, IADR Program and Abstracts of Papers, No. 13, 1968.

12. Eden, G.T.; Cratg, R.G.; and Peyton, F.A.: Evaluation of a Tensile Test for Direct Filling Resins, J Dent Res 49:428434, 1970. 